\title{
LA MUJER IMAGINARIA, UNA REFLEXION DE JORGE EDWARDS SOBRE LA HISTORIA CHILENA RECIENTE
}

\author{
María Teresa Rodríguez Isoba \\ Universidad Complutense
}

\section{De Regreso a la literatura Realista Y Testimonial}

El planteamiento riguroso de los problemas del punto de vista o de la perspectiva del narrador siempre implica una visión problemática de las relaciones entre el lenguaje y la realidad de la que se pretende dar cuenta. Con El museo de cera, publicada en 1981, Jorge Edwards había ido más lejos que nunca en esa indagación, y se había acercado -tardíamente por cierto- a cierta actitud muy extendida en la narrativa hispanoamericana a partir de los años sesenta: la que insistía en que la novela era ante todo un hecho de lenguaje, y resaltaba los mecanismos narrativos, la "ficcionalidad" del relato, la liberación de la literatura de cualquier limitación mimética. A pesar de todo, el escritor chileno no consiguió liberarse de las obsesiones personales que había mostrado en sus primeras obras, y con La mujer imaginaria, publicada en 1985, volvió a adoptar una óptica realista y a ocuparse del presente histórico chileno, absteniéndose de ir más allá en las búsquedas experimentales y las formulaciones simbólicas.

En esta su última novela no desaparecen completamente las pretensiones de adoptar un punto de vista original. Avanzado el relato, el lector se encuentra con la "intromisión" directa del narrador, que hasta entonces habia pasado desapercibido, y que ahora se muestra testigo de los hechos e intérprete de los mismos:

Hemos avanzado con la señora Inés hasta los tramos finales de la fiesta. Escuchamos, escondidos detrás de los arbustos, o parados en la os- 
curidad, o suspendidos encima del sauce, ingrávidos e invisibles, su diálogo con el callampero, del cual dedujimos dos cosas interesantes...'

Durante algunas páginas se prolonga esa irrupción del narrador, que se plantea hipótesis sobre hechos o personas que desconoce, indica algún salto de la narración en el espacio y el tiempo -"hemos avanzado en la noche y en el amanecer y hemos asistido a esas dos curiosas conversaciones, pero ahora nos proponemos retroceder un poco" (p. 103)-, y desaparece para siempre, o vuelve a un segundo plano que le permite pasar desapercibido. No del todo, porque en la novela abundan las reflexiones sobre los hechos, o frases de alguna manera explicativas -"por consiguiente, Cristina había crecido" (p. 32); "cesó, pues, el bullicio" (p. 106)- que indican su presencia, y suponen también la de un lector u oyente cercano, a quien las explicaciones van dirigidas. En cualquier caso es difícil separar tales "intromisiones" de los pensamientos que fluyen en la mente de la señora Inés, formulados en estilo indirecto libre, porque el punto de vista de ese personaje sí que es fundamental en la estructuración de la novela. Su importancia es tal que hace que las mencionadas apariciones directas del narrador resulten extemporáneas.

En efecto, eliminadas aquéllas, el relato queda a cargo de un narrador que vacila entre la omnisciencia y la perspectiva de los hechos que puede ofrecer a través de la protagonista, con preferencia por esta última solución, pues la historia narrada es la de la señora Inés, o la de sus recuerdos y vivencias. Tampoco es fácil distinguir entre una y otra: desde ambas se puede explicar un discurso narrativo y descriptivo que por lo general hace uso de la tercera persona y del estilo indirecto, pero que -como ya ocurría en la primera novela de Edwards, El peso de la noche (1965)- no deja claros los límites entre la expresión del pensamiento de los personajes en estilo indirecto libre y los enunciados a cargo de un narrador omnisciente ${ }^{2}$. Por otra parte, y sólo ocasionalmente, en dos de los cuarenta y cuatro capítulos se adopta el punto de

1 Véase Jorge Edwards, La mujer imaginaria, Barcelona, Plaza \& Janés Editores, 1985 , p. 101. En adelante utilizaremos siempre esta edición, por lo que tras las citas nos limitaremos a consignar, entre paréntesis, el número de página correspondiente.

2 Parece indudable que es un narrador omnisciente quien inicia el relato - "a mediados de 1977 , la señora Inés, o misiá Inés, como la conocía mucha gente, hizo un descubrimiento importante" (7) - y en estilo indirecto da cuenta de los pensamientos que cruzan la mente de su personaje:

De repente se acordaba del día, de las circunstancias precisas, y llegaba a la conclusión de que tenía que recuperar el tiempo, aunque fuera tarde, porque, al fin y al cabo, más valía tarde que nunca..."(7). 
vista de la joven Cristina, cuyos monólogos narran sus vivencias en primera persona. Estas variaciones no dan demasiada complejidad formal a la novela, tal vez la menos complicada entre las escritas por Edwards. Esa sencillez va aparejada sin duda a la opción por el realismo, y quizás a la pretensión de dar preponderancia al contenido del relato sobre los recursos empleados para desarrollarlo.

Otra vez nos encontramos ante una historia sobre burgueses chilenos que se encuentran en un período crítico. Todos los de la reciente historia de Chile lo son, y es evidente que las obras de Edwards constituyen variaciones sobre un mismo tema. Ahora el lector se encuentra de nuevo con un análisis sociológico profundo, a través de la biografía de Inés Vargas Elizalde, una mujer de la clase alta que a los sesenta años descubre que no ha vivido realmente, y se propone recuperar el tiempo perdido.

\section{La estructura De la Novela}

La mujer imaginaria consta de tres partes claramente delimitadas, con quince, trece y dieciséis capítulos respectivamente, y de un breve epílogo. Lo que se cuenta en cada una de ellas es, en un exagerado resumen, lo siguiente:

I) En julio de 1977, el día en que cumple sesenta años, Inés Vargas Elizalde advierte que ha malgastado su vida. La primera parte de la novela se dedica fundamentalmente a rememorar el pasado, y la anciana recuerda su infancia, sus primeros amores, alguna humillación aún viva, su prometedora capacidad para la pintura. Evalúa también su vida de mujer adulta, signada por la trivialidad, el miedo y la sumisión, condicionada por su pertenencia a la alta burguesía, a una familia social y políticamente conservadora. Desde un principio tiene clara la voluntad de

Basta con avanzar unas líneas para que se plantee la imposible (y tal vez inútil) distinción entre un posible enunciado directo del autor omnisciente o la formulación en estilo indirecto libre de los pensamientos de la señora Cristina (el paréntesis nos pertenece):

Y (ella pensaba que) había vivido, entonces, bien, de una manera honorable, con toda la dignidad que le correspondia, pero su vida había sido una vida básicamente mediocre. tristona, donde las alegrias se habían dado en forma secundaria. sucedánea. como los premios de consuelo. (7-8) 
cambiar de existencia y de recuperar el tiempo perdido, y el primer paso es una nueva valoración de sus antepasados, entre los que cobra de pronto extraordinario relieve su tío Salustio, la vergüenza de la familia, un pintor olvidado tras haberse acercado al éxito en épocas ya lejanas.

II) Con su dedicación a la pintura y la separación de su esposo, comienza el proceso de emancipación de Inés Elizalde. El arte le permite relacionarse con otros ambientes y otras clases sociales, mostrar su verdadera personalidad y pisar sus propios territorios. Con una óptica nueva, observa la crisis cada vez más acentuada de su familia, y se interesa en especial por su nieta Cristina. A través de ésta, descubre los problemas de la juventud actual, y trata de identificarse con ella.

III) Inés Elizalde da un paso más, para acercarse a los problemas sociales y políticos del Chile contemporáneo. Sabe ahora de la miseria en las poblaciones marginales, y de la responsabilidad del régimen militar en la tortura y los asesinatos. A la vez comprueba, por los efectos de la crisis sobre su propia familia, que la dictadura tampoco ha sido beneficiosa para la economía del país. El arte se va configurando también como salida frente a la represión, y como una posibilidad de compromiso.

La mujer imaginaria, como puede advertirse, es una novela cuidadosamente estructurada: sin necesidad de fijar unos límites demasiado estrictos, cabe concluir que la primera parte está dedicada a la búsqueda del tiempo perdido; la segunda a mostrar el proceso de emancipación de la protagonista, que a la vez se enfrenta a los problemas personales y familiares del presente, y la tercera a su adquisición de una conciencia social y política. Espacios y tiempos en que discurre el relato están estrechamente relacionados con esa distribución del material narrativo. Se cuenta desde el presente, un presente que se inicia a finales de julio de 1977 , cuando, como se ha dicho, con ocasión de su sesenta cumpleaños la señora Inés descubre que el miedo la ha acompañado a lo largo de casi cincuenta años y que está sola, mientras su marido la engaña y su hijo se embarca en negocios absurdos. Desde ese momento se desencadena el proceso de su autodescubrimiento, un proceso que dura meses y años, pero que en el relato se reduce a los momentos más relevantes, los que despiertan los recuerdos y la deciden a buscar su propio destino.

Desde ese presente se producen las retrospecciones que llevan al pasado, o más bien a pasados diversos, difíciles de precisar aquí, pues 
las rememoraciones son muy abundantes, con el menor pretexto, y con frecuencia breves. Las más significativas, las que configuran la primera parte de la novela, constituyen el análisis de la trayectoria seguida por la protagonista hasta el momento en que se inicia el relato. El pasado más remoto a que se hace referencia tiene su escenario en Valparaíso, en los años veinte, con los recuerdos más lejanos en que aparece el tío Salustio. Después pueden situarse los que se refieren al traslado de la familia a Santiago, a una casa de campo situada al parecer al oeste de la ciudad, en torno a 1930. Con ese cambio de escenario se inicia una breve pero importante etapa en la cual la entonces adolescente vive sus mejores momentos, de euforia y revelaciones que la marcarán para siempre: descubre el amor y el arte, y de ambos deja testimonio en un cuaderno que sus familiares encuentran escandaloso y condenan al fuego. Con ese episodio humillante se inició su sumisión al orden establecido, y ya sin demasiado entusiasmo puede recordar su matrimonio, el reingreso a la casa grande tras la muerte de sus padres, y otros momentos de alguna relevancia en una existencia anodina que concluye ahora. El proceso de autoanálisis se cierra cuando ha aprendido a ver, y comprende que "el papel de misiá Josefa, su madre, había consistido en tenerlos a todos con los ojos vendados. Por eso había cubierto, bajo una frazada ignominiosa, el producto de la extravagancia y la locura del tío Salustio, el mayor y el caso perdido, perverso y perdido, entre sus hermanos, y por eso habia condenado a las llamas su cuaderno, el cuaderno de sus primeras visiones y revelaciones." (p. 85).

Las fechas en que ocurren los acontecimientos del pasado no se consignan, Edwards se limita a indicarlas vagamente, como corresponde a recuerdos lejanos. Las que enmarcan el presente de los hechos narrados en esta primera parte de la novela, por el contrario, sí son precisas: el cumpleaños que pone en marcha el proceso de la protagonista se celebra en julio de 1977 , y la boda de la nieta que cierra esa etapa, con las decisiones que han de condicionar la actuación futura, tiene lugar en la segunda semana de abril de 1978. El pasado es determinante en ese proceso, y los saltos del tiempo presente a otros vividos con anterioridad son constantes, con lo que se rompe de continuo la sucesión cronológica y causal de los acontecimientos. Esas transiciones dan agilidad a la narración, compensando el tempo lento exigido por el carácter reflexivo del discurso.

Las fechas que encuadran el presente en que transcurren los hechos narrados en la segunda parte también están claramente delimitadas: la primera es la de la boda citada, en abril de 1978, y la segunda corresponde al momento en que la protagonista expone por primera vez sus pinturas, en abril de 1981. A lo largo de esos tres años la señora Inés se separa de su marido para irse a vivir a una "casucha" 
próxima a la gran casa de la familia, y se dedica en cuerpo y alma a la pintura. Es un período de acción, en el que las rememoraciones juegan ya un papel de menor importancia: el proceso de autoconocimiento está a punto de concluir o puede darse por concluido, y apenas necesita completarse con testimonios que recoge la protagonista sobre la vida de Salustio, sin duda el personaje más importante en la genealogía que ella elabora para sí. La experiencia vivida por su tío en el París ocupado por los alemanes es el fragmento más importante del pasado que ahora se incluye, $y$, al atenuarse la importancia de los recuerdos, el presente gana relieve. Por otra parte, son los hechos que abren y cierran el período los más significativos y los que ocupan mayor número de páginas.

La tercera parte carece de fechas precisas para los sucesos acaecidos, aunque un nuevo cumpleaños permite situar con cierta aproximación algunos acontecimientos. Bastantes meses antes de ese julio de 1982, la señora Inés ha escuchado el primer testimonio de las torturas y de los asesinatos cometidos por el régimen militar, y es reciente la crisis definitiva del matrimonio de su nieta Cristina; pocos días después se realiza el viaje a las poblaciones marginales, y no mucho más tarde cabe suponer que la protagonista participa por primerá vez en una manifestación contra el régimen y vuelve a golpear la cacerola en señal de protesta, como hiciera en los tiempos de Allende. Pero no importan tanto las fechas concretas como el periodo en sí, muy significativo por el agravamiento de las dificultades económicas del país y la firmeza que adquiere la oposición al gobierno. Ahora las urgencias del presente acaparan la atención, y el pasado carece de relieve. El narrador se limita a la relación lineal de los hechos, apenas interrumpida por alguna breve referencia al pasado y por uno de los monólogos de Cristina.

Queda, naturalmente, el epílogo, que resume brevemente lo sucedido en los dos años que siguen a la muerte de Joaquín, el marido de la protagonista, probablemente ocurrida a finales de 1982. El presente de los hechos narrados, en consecuencia, se iniciaría en julio de 1977 para concluir a fines de 1984 .

El lector puede ignorar estas precisiones cronológicas, y juzgarlas innecesarias para la comprensión del relato. Su interés, sin embargo, es evidente: Edwards ha seguido minuciosamente la evolución de los problemas políticos del país, y sobre todo la de los problemas económicos y sociales. Las peripecias que viven la señora Inés y su familia son inseparables de ese proceso, y la precisión de la cronología deriva de un notable esfuerzo del autor para dar a su historia el fondo histórico adecuado, en estrecha relación con sus pretensiones de realismo.

Otro tanto cabe decir de los escenarios utilizados, cuya descripción, en la medida en que se hace, se ajusta con rigor a la realidad de los lugares en que supuestamente se desarrollan los hechos. El habi- 
tante de Santiago puede reconocer en la novela ámbitos familiares, e incluso encontrará reflejada la transformación sufrida por algunas zonas capitalinas a lo largo de las últimas décadas, y en especial bajo el gobierno de los militares. Esa transformación es la que afecta a la casa de campo de la familia, con el tiempo rodeada de edificios y al final derribada para dejar su sitio a construcciones modernas. Pero esos escenarios reconocibles, descritos con precisión variable, son simplemente eso, los escenarios apropiados y necesarios para desarrollar con verosimilitud rigurosa la historia narrada, y carecen en apariencia de cualquier otra pretensión, incluso los interiores, por lo general acordes con la personalidad de quienes los ocupan, pero sin la condición simbólica evidente que los escenarios tenían en algunas de las obras anteriores de Edwards.

\section{Los Personajes}

Puesto que La mujer imaginaria es la descripción del proceso que sigue la señora Inés hasta encontrar un territorio físico y espiritual propio, los personajes -más bien el personaje- constituyen elementos fundamentales en la construcción de la novela. Junto a la protagonista se dibujan con especial cuidado los caracteres de su tío Salustio y de su nieta Cristina, que sirven de puntos de referencia desde el pasado y hacia el futuro. A su lado los demás personajes desempeñan distintas funciones, pero son de importancia considerablemente menor.

Como habrá podido comprobarse, la vida de la protagonista ofrece dos etapas en el pasado: la inicial de la niña independiente, rebelde y audaz, cuyas pinturas y escritos escandalizan a sus familiares por su precoz significación erótica, y la posterior de mujer de familia acomodada y conservadora, siempre a la sombra de un hombre al que tal vez nunca amó verdaderamente, y con el que tampoco tuvo unas relaciones sexuales satisfactorias. Durante ese largo período fue "la señora joven, perfecta, que esperaba guaguas de vez en cuando y que apoyaba a su marido en sus tareas de diputado colchagüino. Que le organizaba comidas políticas y que se esfumaba con discreción en el momento oportuno, cenando en su dormitorio del segundo piso, junto a los niños" (p. 48), y en época aún reciente "había salido a la calle, furibunda, armada de una cacerola nueva, de aluminio, y de un cucharón reluciente" (p. 108). Nunca tuvo dificultades, ni le faltaron ocupaciones, pero desde el presente tiene la sensación de haber transitado siempre territorios ajenos, de haber defendido opciones que no eran las suyas, de 
haber sido siempre un apéndice de alguien. Ahora ya no es o no quiere ser la mujer que fue, y los valores de su mundo le son íntimamente indiferentes, incluido el marido que la engaña.

Cristina representa a la juventud actual, libre de un pasado "lleno de telarañas": "Nada me gusta más -declara la protagonista- que esta juventud de ahora, que busca cosas diferentes, que se mueve de un lado para otro, aunque a cada rato le den palos en la cabeza" (p. 139). Su nieta es buen ejemplo de esa búsqueda desorientada de sensaciones nuevas, de experiencias inéditas, en las que juegan un papel importante las relaciones sexuales, los estupefacientes y hasta las sectas religiosas. Así se sitúa al margen de los valores de la familia, hasta que ese orden le tiende una trampa, tal vez la más tradicional: se casa con Perico por decisión de sus padres y el matrimonio fracasa estrepitosamente. La abuela observa con inquietud que su proceso se repite en Cristina, pero ahora está en condiciones de tenderle una mano para salir de una crisis profunda que había llegado a suscitar en la joven la idea del suicidio. La señora Inés ayuda a su nieta a liberarse de sus fantasmas para volver a vivir, y su nieta la pone en contacto con la triste realidad social de Chile. Juntas penetran en los ignorados territorios de la pobreza, en las poblaciones marginales de Santiago, infierno de suciedad, de desnutrición y de otros efectos de la miseria absoluta, y juntas se manifiestan contra el régimen militar. Después, tras la ruina económica que determina el fin de la familia, buscarán salidas personales y serán capaces de sobrevivir.

Con ellas parece haber hallado Edwards nuevos caminos: de manera ambigua con Cristina, de la que al final sabemos que se ha casado de nuevo, pero ignoramos el precio que ha tenido que pagar por la estabilidad afectiva; de modo evidente con la señora Inés, sin duda uno de los personajes más complejos y mejor elaborados que ofrece su obra literaria. La protagonista de La mujer imaginaria constituye una novedad muy notable en la narrativa del escritor chileno: es el primer personaje al que la rebeldía parece llevar a alguna parte, el primero que encuentra la salida del tedio y de la decrepitud moral, y eso indica un cambio indudable de actitud en el autor, aunque en su última novela también abundan los personajes que de un modo u otro fracasan, o se someten al orden establecido, o, como en el caso de Salustio, eligen un camino equivocado y se extravian, se marginan al precio del fracaso, de la degradación, la locura o la muerte.

Puesto que sirve de referencia constante en la historia de la protagonista, es necesario detenerse en la función que dentro del relato desempeña el tío pintor, cuya vida es una transgresión constante de las normas que rigen la vida de la familia. Su final es interpretado por algunos de sus parientes como el justo castigo de sus culpas, $y$, en consecuencia, cabe pensar que es una víctima del orden que trataba de 
destruir. Sin embargo, las reflexiones que le dedica Inés Elizalde le dan una significación más compleja: en su proceso de análisis, "perseguía imágenes pasadas, gestos que no había sabido descifrar a su debido tiempo. El tío Salustio concentraba los gestos y las imágenes oscuras, marginales, que el tribunal de la familia había condenado. Ella había sentido una curiosidad intensa, apasionada, y después, a partir del día de su desgracia, a partir del día de su degradación, a partir del crepúsculo del holocausto de su cuaderno, contra la pared de adobe, la había descartado" (p. 109). El recuerdo de Salustio se asocia siempre con la curiosidad que ahora trata de recuperar, con el perturbador descubrimiento de la sexualidad, con la parte de su personalidad oculta y reprimida desde que se vio obligada a aceptar las normas de comportamiento impuestas por su familia. Las razones de esa relación son evidentes: Salustio no significa sólo la trasgresión de determinadas convenciones sociales, sino también la exploración de los abismos de la propia personalidad, la inmersión en dominios ocultos y tal vez sagrados, el conocimiento del mal que se paga con la locura y la muerte. Si su sobrina evita este destino es porque descubre que es el futuro lo que le interesa, cuando, con los restos chamuscados del viejo cuaderno en sus manos, "resolvió, entonces, que ya no quería releer ese cuaderno: si lo hubiera descubierto completo, sin las mutilaciones infligidas por la sentencia de misiá Josefa, tampoco lo habría releído" (p. 172).

En esa actitud radica fundamentalmente la diferencia entre la protagonista de La mujer imaginaria y la gran mayoría de los personajes de Edwards: ella decide vivir el presente con plenitud y orientada hacia el futuro, mientras los demás se degradan en un tiempo estático o circular, ocupados con frecuencia en la exploración permanente de sus miserias o de las miserias de la condición humana. Inseparable de esa actitud es la función que se asigna a la pintura, instrumento que Salustio utilizó para la exploración de las dimensiones ocultas del universo y de su personalidad tortuosa y atormentada, y que la señora Inés pretende orientar en bien distinto sentido:

¿No era posible, se preguntaba, y se lo preguntaba hacía poco, porque antes, simplemente, evitaba asomarse a esos conflictos, a esos abismos, que el arte, en vez de dirigirse al mal, a lo caótico, a lo perverso, buscara el bien, la armonia, una belleza que derivara, que consistiera en armonía? ¿No podría ella, justamente, después de cumplir sus sesenta años, por tarde que fuera, asumir esa otra alternativa? Aunque no consiga resultados, pensaba. Porque sería, por los menos, un objetivo digno. ¿No bastaba con proponerse un objetivo digno? (p. 49.) 
Algún tiempo después la protagonista anunciaría que "iba a pintar de otra manera, y que se proponía salir adelante, en lugar de hundirse, como el tío Salustio, en un pozo negro" (p. 101). A partir de aquí las diferencias entre los dos personajes se acentúan progresivamente, y sobre todo desde el momento en que Inés Elizalde sale de sí misma para enfrentarse a su entorno, para descubrir las desdichas amorosas de su nieta y la represión del régimen militar; ante tanto dolor inútil, tratando de resolver los nuevos problemas que se le planteaban, "se preguntaba cómo hacerlo, se preguntaba con tanta insistencia que llegó a sospechar que la pintura no tenía, tampoco, demasiado sentido, que no era una respuesta suficiente" (p. 203). Eso no significará el abandono del arte, que sirve para plasmar en colores los nuevos descubrimientos, pero esas actividades han de completarse con otras de carácter social y político, respuesta a las urgencias históricas inmediatas: sólo golpeando la cacerola constata que "se había puesto a combatir, sin miedo ni vergüenza de nada, y comprobaba que el mundo tenía que amoldarse a ella en alguna medida. ¡La lucha no era inútil!" (p. 256).

Esa conciencia salva a la protagonista del descalabro general de la familia, y de los fracasos sucesivos que sus exposiciones posteriores que en algún momento le hicieron creer que la historia se repetía, que de nuevo se encontraba en el instante de la adolescencia en que los dibujos de su cuaderno provocaron carcajadas estridentes y miradas burlonas. Pero esta vez no se resigna a la derrota, el paso dado era definitivo: "Qué mejor podía ocurrirle, a esa edad, que estar en plena lucha? No tenía el poder, pero conservaba sus energías intactas, y el poder tendría que contar con eso" (p. 270). La pintura podía ayudar a ver de nuevo, a pesar de la represión. Su soledad tenía un sentido.

\section{Sobre la Significación Polftica de la Novela: la función Del arte Y De la literatura}

Indudablemente La mujer imaginaria tiene unos contenidos políti$\cos$, que Edwards sabe introducir sin que la obra se vea afectada negativamente. Hay que destacar la exactitud de las referencias a la situación chilena durante los años que abarca el presente del relato, con las cuales el autor inserta en espacios y tiempos muy concretos una nueva historia sobre la ruina y desaparición de una familia burguesa, ahora más evidente que nunca. Esto es lo que queda tras el descalabro económico: 
...una casucha solitaria, detrás del esqueleto de un edificio en construcción; una mujer anciana y aquejada de una extravagancia súbita, de algo parecido a una crisis senil; una niña que trataba de colocar trabajos en las revistas femeninas para ganarse unos pesos; un hijo que hacía sólo un par de años estaba lleno de proyectos fabulosos, canchas de golf a la orilla de las ensenadas, sobre lomajes suaves, y que ahora había tenido que hacerse humo, mientras las canchas, si es que habían existido alguna vez, iban siendo tragadas por espigas silvestres, nidos de chercanes, madrigueras de conejos". (pp. 266-267)

Al hilo de los recuerdos, no faltan las referencias indirectas a la historia pasada del país, pero, a diferencia de lo que Edwards había hecho en Los convidados de piedra (1978), la atención se centra ahora casi exclusivamente en el presente de la narración, en el período que va de mediados de 1977 a finales de 1984. El narrador no suele dar cuenta directamente de la situación que vive Chile durante esos años, y la información se ofrece por medio de los diálogos circunstanciales de algunos personajes. Así, con ocasión de la boda de Cristina, sabemos que los recelos y la desconfianza de años anteriores se han diluido, que se ha atenuado el rigor de los primeros tiempos del régimen; sabemos también de los "Chicago Boys" - "hombres jovenes, bien vestidos, casados con mujeres vistosas, que discurseaban, intercambiaban palmotadas en los hombros, se reían a carcajadas, bebiendo sus whiskys, y que parecían la encarnación de la vitalidad, del optimismo, del éxito" (p. 91)-, que inspirarían la política económica del régimen en los años sucesivos; sabemos de los muchos partidarios de un gobierno militar que ha conseguido orden y progreso, de quienes creen hallarse "en la antesala de los mejores tiempos" (p. 94). No faltan, desde luego, las voces discrepantes: a propósito del esplendor que rodea la boda, "alguien, y puede que no le faltara razón, decretó que era un anacronismo, un canto de cisne, el último de los matrimonios a la antigua usanza" (p. 92). Hay miembros de la clase alta tradicional que ven amenazados sus privilegios por las verdades de la economía de mercado, invadidos sus territorios por nuevos ricos, "gente rara, desconocida, que había salido de no se sabía donde" (p. 94), ajena a los valores y comportamiento de las grandes familias de siempre, pero ese entendimiento de crisis se diluye en el optimismo general, el mismo que animó al hijo de la protagonista cuando se embarcó en los negocios absurdos que causarán años más tarde la ruina general y lo forzarán a salir del país huyendo de la justicia. Por entonces cualquier temor resulta injustificado, el despegue de la economía nacional parece inminente: "Ligerito oiremos hablar del milagro chileno" (p. 67), asegura el marido de la protagonista, a fines de 1977. 
La confianza en el futuro del país y en la política económica del gobierno alcanza su momento culminante -Edwards es riguroso al seguir el proceso real- en 1981, a la vez que empiezan a advertirse ya sus debilidades. La fiesta con que Inés Elizalde celebra el éxito de su exposición es el pretexto esta vez para que se manifiesten distintas opiniones: la de quien entiende "que el boom de la economía era una cosa nunca vista, un verdadero milagro" (p. 170), y la de quien comenta "que ese boom podía ser otro producto de la fantasía criolla, de la inextinguible capacidad de los chilenos para fabricar mitos" (p. 170), y entiende que el milagro sólo es "una mezcla perfecta de especulación pura, enteramente improductiva, y de esoterismo" (p. 171).

Y después el desastre: a mediados de 1982 empiezan a confirmarse los temores de los más desconfiados, mientras la protagonista comprueba la desesperada situación de miseria en que viven las poblaciones marginales de Santiago. Pronto los síntomas de la crisis se dejarán sentir por todas partes, en la ruina de los que habían arriesgado demasiado para enriquecerse, pero sobre todo en el empobrecimiento general, en las restricciones que pronto afectan a la mayoría de la población. Con el tiempo la crisis económica no hará sido acentuarse, y esa es la razón histórica fundamental para explicar la progresiva pérdida de apoyo sufrida por el gobierno militar a lo largo de los últimos años. Edwards, desde luego, no se detiene en el examen de esa relación evidente: se limita a dejar constancia de la quiebra económica y de la creciente oposición al régimen de Augusto Pinochet, y sólo en la medida en que enmarcan la evolución ideológica de la protagonista o de su nieta Cristina. A pesar de eso -y tal vez por la apariencia de objetividad que deriva de un narrador que no se pronuncia sobre cuestiones marginales al relato- La mujer imaginaria tiene especial interés para quien busque información sobre la evolución social y política de Chile en los últimos años.

Insertada en un contexto histórico preciso, la decadencia de la alta burguesía tradicional ya no es -como ocurría en los relatos anteriores de Edwards- la expresión literaria de una cosmovisión negativa, el símbolo de una civilización en decadencia: es sobre todo el resultado de unas circunstancias concretas que llevan a la ruina a unos personajes bien determinados. Eso no quiere decir que no se manifieste también una evolución histórica general, uno de cuyos síntomas es el desclasamiento, la eliminación de las barreras tradicionales que incomunicaban a los distintos estratos de la población chilena: para los privilegios exclusivos de las grandes familias de siempre, son más nocivas las alteraciones producidas por los vaivenes de la economía libre de mercado -que permiten el enriquecimiento de los más hábiles, sin tener en cuenta su procedencia social- que los efectos derivados de los sucesivos cambios de gobierno. Desde luego, se ponen de manifiesto una 
vez más las debilidades de la burguesía y su incapacidad para hacer frente a los nuevos tiempos, pero tales limitaciones afectan a la clase en su conjunto y a sus miembros en particular. Su alcance nada tiene que ver con la condición humana en general, y lo demuestra el mero hecho de que alguien pueda sustraerse al destino común, circunstancia que no se registraba en otras ficciones de Edwards. La experiencia de Inés Elizalde demuestra que los destinos son individuales, y que uno puede salvarse con su propio esfuerzo.

Por el contrario, si puede deducirse un mayor alcance para las reflexiones sobre la inestabilidad política y la represión de los regímenes militares. Edwards muestra el progresivo descubrimiento de la verdad sobre las torturas y los asesinatos, una realidad que buena parte de la sociedad chilena había decidido ignorar, convirtiéndose de alguna manera en cómplice del gobierno represor. Al menos esa es la sensación que experimenta Inés Elizalde tras escuchar el testimonio de una de las víctimas, y sólo entonces "empezó a leer las noticias del país y a interpretarlas de otra manera, atando cabos, haciendo relaciones entre fenómenos diferentes, comprendiendo el significado de sucesos que antes no comprendía, como el hallazgo de unas osamentas, o las revelaciones sobre un crimen horrible, perpetrado por funcionarios de la policía secreta en una ciudad del Norte" (p. 187). No le faltará ocasión de comprobar las dimensiones de la tragedia: encarcelamientos, torturas, asesinatos, desaparecidos, exiliados, campos de concentración. La constatación de tanto sufrimiento absurdo es determinante en la evolución de sus actitudes políticas.

El alcance a que nos referíamos sólo en parte tiene que ver con la casuística particular de la represión chilena: deriva de las reflexiones del poeta que cuenta a la protagonista su dramática experiencia, asociada a unos versos de Borges:

Yo que anhelé ser otro, ser un hombre de sentencias, de libros, de dictámenes, a cielo abierto yaceré entre ciénagas; pero me endiosa el pecho inexplicable un júbilo secreto. Al fin me encuentro con mi destino sudamericano... (p. 182)

Como es bien sabido, el "Poema conjetural" recrea las últimas palabras de Francisco Narciso Laprida, a punto de morir a manos de los montoneros del fraile Aldao, allá por 1822. "Al fin y al cabo -explicaba el poeta chileno-, Laprida era un hombre de letras, como su des- 
cendiente Borges, y como él, que iba a morir a manos de un grupo de salvajes, por obra de un destino ciego" (p. 181). La elección de un escritor tan ajeno a la literatura politizada o de protesta es significativa: la reflexión va más allá de los avatares de un momento histórico particular, más allá de unas víctimas y de unos opresores concretos, para fijarse en las manifestaciones reiteradas de una violencia irracional, de una crueldad injustificada, constante o al menos cíclica. Francisco Narciso de Laprida comparte con las víctimas de la represión chilena un destino común, el de ser aniquilados por la brutalidad del mundo sudamericano. El fatalismo es evidente en esa visión de los problemas de Hispanoamérica: sus habitantes parecen irremediablemente a merced de una violencia gratuita, condenados a un infierno cuyos ocupantes - como diría Inés Elizalde a propósito de quienes sufren la miseria de las poblaciones marginales- "no son necesariamente pecadores". (p. 216)

Otro aspecto de interés, en estrecha relación con los contenidos políticos de la novela y con su visión del mundo americano, es el relativo a la función individual y social que el arte puede desempeñar. En La mujer imaginaria no faltan los testimonios de la actitud variable, aunque siempre represiva, del gobierno militar, y queda constancia de la censura que afecta a la prensa, a los libros, al teatro, a la pintura y a cualquier otra manifestación cultural. Las referencias, una vez más, se ajustan con rigor a la situación real, y en este aspecto el relato también constituye una fuente de información sobre la historia reciente de Chile. En ese contexto, la trayectoria que sigue la protagonista, haciendo del arte una vía de salvación personal y una forma de compromiso con su entorno, se vuelve necesariamente significativa.

Las diferencias entre Inés Elizalde y Salustio merecen especial atención, examinadas desde este punto de vista. El convirtió la pintura en una agresión contra la pobreza intelectual y la moralidad pacata del medio familiar y nacional, y se alejó mientras pudo de ese país de indios y de salvajes, seguro de que el ambiente europeo era el más adecuado para desarrollar sus actividades artísticas; su labor creadora, por otra parte, parecía inseparable de la inmersión en el reino del mal, en las zonas más oscuras de su compleja personalidad. También para la protagonista el arte era fundamental en su tarea de autoconocimiento, pero advirtió a tiempo los riesgos y la inutilidad de mirar exclusivamente hacia el pasado o hacia uno mismo. En consecuencia, creyó necesario que su actividad artística asumiese la función de buscar la armonía y el bien, que fuese una forma de vivir la aventura de cada día, una posibilidad de seguir adelante. Ese es el primer paso hacia un compromiso con el entorno. Después, frente al sufrimiento de la población chilena, comprende que la pintura no es una respuesta suficiente, pero también descubre "que la represión impide ver, y que la 
visión, en cambio, la visión sin prejuicios y sin velos, es el comienzo, el gran comienzo" (p. 271). Esta revelación afecta a todos los órdenes de la vida, y en consecuencia tiene que ver también con la realidad política: su tarea de pintora es una contribución, por insignificante que sea, para que la verdad se ponga de manifiesto, para que se haga la luz sobre la triste realidad del país. Si atribuimos esa función a la literatura, tal vez hayamos acertado con la intención de .Edwards al escribir La mujer imaginaria: esta es su contribución a que la esperanza se mantenga, y a la vez una reflexión sobre su propia trayectoria como creador. El desencanto absoluto de sus obras anteriores ha desaparecido, ahora es preciso demostrar que los cambios son posibles y hay que luchar para conseguirlos, aunque sean personales e imperceptibles. 